\title{
Cross-Sectional Dispersion and Expected Returns
}

\author{
Thanos Verousis ${ }^{\mathrm{a}}$ and Nikolaos Voukelatos $\mathrm{b}^{\mathrm{*}}$ \\ ${ }^{a}$ University of Bath \\ ${ }^{b}$ University of Kent
}

\section{May 2017}

\begin{abstract}
This study investigates whether the cross-sectional dispersion of stock returns, which reflects the aggregate level of idiosyncratic risk in the market, represents a priced state variable. We find that stocks with high sensitivities to dispersion offer low expected returns. Furthermore, a zero-cost spread portfolio that is long (short) in stocks with low (high) dispersion betas produces a statistically and economically significant return. Dispersion is associated with a significantly negative risk premium in the cross-section $(-1.32 \%$ per annum $)$ which is distinct from premia commanded by alternative systematic factors. These results are robust to stock characteristics and market conditions.
\end{abstract}

JEL classifications: G11; G12

Keywords: Cross-sectional dispersion; cross-section of stock returns; pricing factor

\section{Introduction}

The cross-sectional dispersion (CSD) of stock returns captures the extent to which individual stocks offer returns that cluster around (or diverge from) the return of the market, thus providing a natural measure of stock heterogeneity at the aggregate level. Moreover, given that

${ }^{*}$ Correspondence to Nikolaos Voukelatos, Kent Business School, University of Kent, Canterbury CT2 7PE, UK. Email: n.voukelatos@kent.ac.uk. Tel.: +44 (0) 1227827705. 
the distance of a stock's return from the market return is driven by idiosyncratic shocks, crosssectional dispersion essentially reflects the aggregate level of idiosyncratic risk in the market. In this paper, we provide evidence that dispersion constitutes a priced state variable associated with a negative risk premium in the cross-section of individual stock returns.

The recent literature has been paying increasing attention to stock return dispersion in various contexts, such as forecasting market returns (Garcia et al., 2014; Goyal and Santa-Clara, 2003; Maio, 2015) and economic conditions (Angelidis et al., 2015; Chen et al., 2011). ${ }^{1}$ Our paper contributes to the literature on the relationship between dispersion and returns by examining the role that dispersion plays in determining the returns of individual stocks. Furthermore, we contribute to the literature by providing evidence of dispersion being priced in the cross-section of stock returns.

The forecasting power of aggregate idiosyncratic risk over market returns is still a debated topic. On the one hand, Goyal and Santa-Clara (2003) were among the first to report that the mean stock variance can be used to forecast market returns, while the market variance itself does not have a similar forecasting power. Furthermore, they find that this predictive relationship stems primarily from the idiosyncratic component of the average stock variance, which can be measured by the cross-sectional dispersion of stock returns. On the other hand, Bali et al. (2005) suggest that the positive relationship between aggregate idiosyncratic risk and subsequent market returns that is reported by Goyal and Santa-Clara (2003) is driven by small stocks and partly reflects a liquidity premium, with the forecasting power also disappearing when the sample period is extended. Wei and Zhang (2005) further support the claim that the strong positive relationship between aggregate idiosyncratic risk and market returns is samplespecific rather than a robust finding.

However, some more recent studies have provided additional evidence in support of aggregate idiosyncratic risk constituting a significant predictor of market returns. For instance, Pollet and Wilson (2010) report that the mean variance of individual stock returns is negatively related to the future returns of the aggregate market. Bernales and Valenzuela (2016) and Buss et al. (2017) show that the correlation implied from option contracts can forecast subsequent market returns. While it is not linked to aggregate idiosyncratic risk in particular, implied correlation in these papers is argued to be an indicator of market-wide risk and, importantly, to

\footnotetext{
${ }^{1}$ Another stream of the literature has used the cross-sectional dispersion of asset returns as a measure of investors' herding. A substantial number of papers have focused on the cross-sectional dispersion to examine herding effects in the stock market (Chiang and Zheng, 2010; Galariotis et al., 2015), the options market (Bernales et al., 2016), and the market for corporate bonds (Cai et al., 2012).
} 
contain information about future market returns.

Garcia et al. (2014) argue that the cross-sectional dispersion of stock returns has the advantage of being a model-free, consistent and asymptotically efficient estimator of aggregate idiosyncratic risk. Moreover, they find that dispersion has a significant predictive ability over future market returns when examined at the monthly and daily frequency. Maio (2015) provides an even more comprehensive examination of the dispersion-returns relationship by focusing on forecastability over multiple horizons. Using the returns of portfolios rather than stocks to compute the cross-sectional dispersion, Maio (2015) finds that dispersion and the market variance are both related to future market returns. Dispersion, in particular, is strongly negatively associated with excess market returns, and this relationship is found to be robust across multiple forecasting horizons (see Guo and Savickas, 2008, for evidence on the G7 countries). Other studies provide supporting evidence of a significant relationship between dispersion and the returns of value and momentum premia (Angelidis et al., 2015; Bhootra, 2011; Connolly and Stivers, 2003; Stivers and Sun, 2010).

Despite the substantial empirical evidence on the forecasting power of dispersion over market returns, the relationship between dispersion and individual stock returns has not been explored thus far. Garcia et al. (2014) represent a potential exception since, even though their focus is on market returns, they briefly examine whether dispersion can price the 25 and 100 size/book-to-market portfolios after controlling for the standard three Fama and French (1993) factors. In this paper, we examine if dispersion is a priced factor in the cross-section of stock returns in a comprehensive way. Throughout the paper, our emphasis is on whether stocks' expected returns are driven by their sensitivity to dispersion, after accounting for a large set of other systematic factors and stocks' idiosyncratic characteristics.

Our research question is distinct from the literature on the relationship between the expected returns of individual stocks and their own level of idiosyncratic risk. For instance, Ang et al. (2006) find that expected returns are negatively related to their idiosyncratic volatility, as computed relative to the Fama and French (1993) model, and this relationship cannot be explained by the stocks' exposure to aggregate volatility risk (proxied by the market's implied volatility index VIX). On the other hand, Fu (2009) computes time-varying conditional expectations of idiosyncratic volatilities based on the exponential GARCH model and finds that they are in fact positively related to stocks' expected returns. In a more recent paper, Cao and Han (2016) also use GARCH-based volatilities as a proxy for a stock's level of idiosyncratic risk and report that the sign of the relationship between idiosyncratic risk and expected returns 
depends on whether a stock is undervalued or overvalued in the first place. Chichernea et al. (2015) further show that this premium for idiosyncratic risk is significantly larger for neglected stocks, i.e. stocks with a small investor base. Finally, Chen and Petkova (2012) report that, when stock portfolios are sorted according to their idiosyncratic volatilities, a negative risk premium is found in the cross-section as compensation for exposure to the mean stock variance but not with respect to the mean correlation.

Our interest in returns' cross-sectional dispersion as a potential state variable is motivated primarily by the fact that it has been shown to act as a useful measure of aggregate idiosyncratic risk. Dispersion's potential role as a systematic factor can be further supported by recent empirical evidence on its ability to forecast economic conditions such as unemployment (Chen et al., 2011), consumption volatility (Garcia et al., 2014) and the business cycle (Angelidis et al., 2015).

The empirical results support the theoretical prediction of dispersion being priced in the cross-section of stock returns. We find evidence of a significant negative premium for exposure to dispersion risk, where expected returns vary according to the stocks' sensitivities to the aggregate dispersion factor. Stocks with higher sensitivities to dispersion are found to offer lower returns. Furthermore, a zero-cost spread portfolio that goes long in stocks with low "dispersion" betas and short in stocks with high betas offers a monthly return of 0.94\% (around $11.3 \%$ on an annual basis). Based on the Fama-French-Carhart alpha, the risk-adjusted return of this portfolio is $0.55 \%$ per month (around $6.6 \%$ per annum) and it suggests that the high return offered by the portfolio is not simply compensation for exposure to well-known systematic risk factors.

We perform a set of robustness tests to ensure that these results are not driven by stocks' idiosyncratic characteristics. We run two-pass regressions of individual stock returns against a set of stock-specific characteristics and we compute the returns of double-sorted spread portfolios. Our results confirm that stocks with different exposures to dispersion risk earn markedly different returns, even after accounting for a large set of idiosyncratic characteristics, with these differences being statistically and economically significant. The stock-specific characteristics that we control for include size, momentum, standard deviation, skewness and kurtosis of historical returns, the dispersion of analysts' forecasts about the firm's future earnings, liquidity, co-skewness with the market, idiosyncratic volatility, and the percentage of returns' variation that can be explained by systematic risk.

We employ the standard Fama-MacBeth (1973) two-pass methodology and estimate that 
the price of aggregate dispersion risk in the cross-section is statistically significant at $-0.11 \%$ per month (-1.32\% per annum). More importantly, we show that this negative dispersion premium is distinct from other risk premia that have been identified by earlier studies and that relate to either uncertainty or heterogeneity of beliefs. In particular, our standard FamaMacBeth (1973) specification accounts for stocks' sensitivities to a set of commonly used factors, namely the market, the Fama and French (1993) size and value factors, the Carhart (1997) momentum factor and the Pastor and Stambaugh (2003) liquidity factor. We also augment the specification to account for stocks' loadings on market volatility (Ang et al., 2006), the aggregate dispersion of analysts' earnings forecasts (Diether et al., 2002), the mean stock variance (Goyal and Santa-Clara, 2003), an index of macroeconomic uncertainty (Bali et al., 2015), and the mean stock idiosyncratic volatility. We find that the negative dispersion risk premium remains statistically significant and at the same level in several versions of the extended specification, suggesting that the risk premium associated with aggregate dispersion is distinct from premia commanded by other systematic factors that might be considered alternative.

The remaining of the paper is organized as follows. Section 2 discusses the rationale for using dispersion as a state variable and presents the data used. Section 3 discusses the returns offered by portfolios formed across dispersion betas. Section 4 presents the results of a battery of robustness checks. Section 5 discusses the price of aggregate dispersion risk in the crosssection. Finally, Section 6 concludes.

\section{Dispersion Measure}

\subsection{CSD as a State Variable}

We compute our main variable of interest, namely the cross-sectional dispersion of stock returns, as the equally-weighted cross-sectional absolute deviation of the returns of individual stocks around the market return

$$
C S D_{t}=\sum_{i=1}^{N} \frac{\left|r_{i, t}-r_{m k t, t}\right|}{N-1}
$$

where $r_{i, t}$ is the return of stock $i$ at time $t$ and $r_{m k t, t}$ is the market return at $t$. As a robustness 
check, we also construct alternative CSD measures by computing (i) squared rather than absolute deviations, (ii) value-weighted (based on market capitalization) rather than equallyweighted deviations, and (iii) deviations around the (equally- or value-weighted) mean stock return rather than the return of the market index. The empirical results are largely the same irrespective of the particular version of the dispersion measure, thus we only report results based on CSD as computed from (1).

Intuitively, cross-sectional dispersion is a measure of the extent to which the returns of individual stocks at a particular point in time tend to cluster around or diverge from the consensus represented by the market return. In other words, CSD is an aggregate measure of the heterogeneity of stock returns and, therefore, is directly linked to the aggregate level of idiosyncratic risk.

The relationship between CSD and aggregate idiosyncratic risk has been highlighted by Goyal and Santa-Clara (2003) and Garcia et al. (2014) who find that the cross-sectional dispersion of stock returns is positively and significantly correlated with subsequent market returns in the US. These results lead Goyal and Santa-Clara (2003) and Garcia et al. (2014) to argue that cross-sectional dispersion can serve as a proxy for aggregate idiosyncratic risk that can be readily computed at any frequency without the need to assume any particular asset pricing model.

We propose that, as a proxy for aggregate idiosyncratic risk, cross-sectional dispersion represents a state variable that should be priced in the cross-section of stock returns. Furthermore, we expect this state variable to be negatively correlated with the consumption and investment opportunity set, therefore implying a negative risk premium for stocks' exposure to dispersion risk.

Starting with the traditional Capital Asset Pricing Model (CAPM), many asset pricing models suggest that idiosyncratic risk does not affect asset returns and that only systematic risk is priced. This premise is typically based on the assumption of a representative agent who has the incentive and ability to fully diversify by investing in the market portfolio. However, the assumption of full diversification is particularly restrictive and highly unlikely to describe the way in which investors actually construct portfolios, since in reality different investors clearly hold equity portfolios that are different from the market portfolio and from one another. To this end, several studies have proposed modified versions of the CAPM where investors hold portfolios that are not fully diversified (Bessembinder, 1992; Levy, 1978; Malkiel and Xu, 1997; Malkiel and $\mathrm{Xu}, 2005$; Merton, 1987). In this type of models, the absence of full diversification 
comes as a result of transaction costs, taxes, investors pursuing distinct investment strategies because of private information or superior skills etc. Irrespective of the specific exogenous reason for holding undiversified portfolios, the main implication of these "partial diversification" models is that assets' expected returns are theoretically determined by their exposure to market risk (as in the standard CAPM) and their exposure to a measure of idiosyncratic risk.

In a more recent paper, Maio (2016) derives an extension of the CAPM where cross-sectional dispersion is priced as a risk factor in addition to the market return. In this two-factor asset pricing model, Maio (2016) assumes a set of heterogeneous investors who hold undiversified equity portfolios by investing in different segments of the stock market. While each of these investors could be considered as representative of a particular group of homogeneous investors, there is no global representative agent as in the standard CAPM.

Assuming a power utility function for each investor and using a second-order Taylor approximation for investors' growth rate in wealth, Maio (2016) shows that the average stochastic discount factor (SDF) in the economy can be written as

$$
M_{t+1}=\delta W G_{t+1}^{-\gamma}+\frac{1}{2} \delta \gamma(\gamma+1) W G_{t+1}^{-\gamma-2} V W_{t+1}
$$

where $\delta$ is a time-subjective discount factor, $W G$ is the cross-sectional average gross growth rate in wealth across all investors, and $V W$ is the cross-sectional variance of wealth growth.

Given an intertemporal budget constraint and that the fact that the sum of all undiversified portfolios corresponds to the market portfolio, the cross-sectional variance of wealth growth can be rewritten as the dispersion of stock returns

$$
V W_{t+1}=\frac{1}{L} \sum_{l=1}^{L}\left(r_{p, t+1}^{l}-r_{m k t, t+1}\right)^{2}
$$

where $r_{p, t+1}^{l}$ is the gross return on investor l's reference portfolio between $t$ and $t+1$. Overall, the SDF can be rewritten as

$$
M_{t+1}=\delta r_{m k t, t+1}^{-\gamma}+\frac{1}{2} \delta \gamma(\gamma+1) r_{m k t, t+1}^{-\gamma-2} C S D_{t+1}
$$


The SDF decreases with the market return and increases with the level of dispersion CSD. Furthermore, the expected return-covariance equation can be written as

$$
E_{t}\left[r_{i, t+1}\right]-r_{f, t+1}=\lambda_{M} \beta_{i, M}+\lambda_{C S D} \beta_{i, C S D}
$$

where $\beta_{i, M}$ and $\beta_{i, C S D}$ refer to the betas of asset $i$ with respect to market risk and dispersion risk, respectively, while the terms $\lambda_{M}$ and $\lambda_{C S D}$ denote the corresponding prices of risk. ${ }^{2}$

A higher level of dispersion means larger idiosyncratic shocks to individual stock returns and a higher level of aggregate idiosyncratic risk. In this state, a stock (or portfolio of stocks) that an investor holds is more likely to be characterized by a higher level of idiosyncratic risk compared to a state where dispersion (aggregate idiosyncratic risk) is lower. Naturally, this relationship will not hold for every conceivable stock portfolio, but it is expected to hold on average. Importantly, this higher idiosyncratic risk for a given asset is not diversified away. Overall, an increase in the cross-sectional dispersion of stock returns has a negative impact on investors' total welfare, representing a "bad" state of the economy.

The above relationship between dispersion and the investment opportunity set is suggestive of a negative premium for exposure to dispersion risk. For instance, a higher level of dispersion means that idiosyncratic risk among stocks is on average higher. In these circumstances, investors who are, for whatever exogenous reason, not fully diversified would prefer to hold assets that covary positively with dispersion, since they would offer their highest returns during periods of higher idiosyncratic (and undiversified) risk at the aggregate level. Consequently, investors would bid up the prices of these assets that act as hedges, and we would expect them to offer lower returns. At the other end of the spectrum, assets that covary negatively with dispersion will tend to offer their highest returns when dispersion is low ("good" state) and perform poorly when dispersion is high ("bad" state). Investors would consider these assets to be less desirable to hold compared to those with positive exposure to dispersion, leading to lower prices and higher expected returns. Overall, we predict a negative dispersion risk premium in the cross-section where, as a stock's sensitivity to dispersion increases, that stock becomes more attractive (less risky) and its expected return decreases.

Finally, the expected impact of dispersion on the consumption and investment opportunity

\footnotetext{
${ }^{2}$ Please refer to Maio (2016) for a much more detailed discussion of the two-factor asset pricing model.
} 
set can be further motivated by the recent empirical evidence on the relationship between dispersion and certain macroeconomic indicators. Chen et al. (2011) find that increases in the dispersion of stock returns are strongly associated with subsequent increases in long-term unemployment rates, while Garcia et al. (2014) report that dispersion is positively related to consumption-growth volatility. More recently, Angelidis et al. (2015) examine dispersion in the G7 countries and find that it correlates strongly with the business cycle and economic growth, with a higher dispersion leading to a higher probability of a recession, an increase in unemployment and a fall in economic activity in the future. These empirical findings provide additional support for the hypothesis that the cross-sectional dispersion of stock returns constitutes a state variable that correlates negatively with investment and consumption opportunities.

Overall, we expect a negative dispersion premium in the cross-section of individual stock returns. As a stock's sensitivity to dispersion decreases (i.e. becomes more negative), that stock becomes riskier and investors would demand a higher expected return to hold it. In contrast, assets that covary positively with dispersion are acting as valuable hedges against undesirable increases in aggregate idiosyncratic risk and, thus, represent safer assets associated with lower expected returns.

\subsection{Data}

We examine the cross-section of equity returns in the US from 2 January 1996 to 31 December 2012. Our dataset of stock prices is from the Center for Research in Security Prices (CRSP) database and it contains, among other fields, daily closing bid and ask quotes and trading volumes of stocks trading in the US market. We use the CRSP value-weighted index as a proxy for the aggregate market when computing the cross-sectional dispersion in equation (1).

Figure 1 plots the resulting time-series of CSD at a daily frequency from January 1996 to December 2012 . The mean daily CSD is $1.16 \%$ with a standard deviation of $0.44 \%$. As can be easily seen from the Figure, the time-series of daily CSD is exhibiting a significant degree of serial correlation, with the first-order autocorrelation, for instance, being equal to 0.91 (serial correlation is similarly pronounced when CSD is computed at a monthly frequency). Therefore, our proposed risk factor that refers to the aggregate cross-sectional dispersion of stock returns is measured as the first difference in $C S D$, denoted as $\triangle C S D$. The time series of first differences $\triangle C S D$ has a mean of effectively zero (around $-0.0001 \%$ ) and a standard deviation of $0.19 \%$, 
while the first-order autocorrelation is significantly lower than the one observed in levels (approximately -0.30).

In Section 5, we explore whether other aggregate factors that relate to either uncertainty in general or to divergence of expectations in particular subsume the explanatory power of $\triangle C S D$. More specifically, we show that dispersion risk is priced in the cross-section after accounting, among other factors, for changes in the implied volatility index VIX, changes in the dispersion of analysts' forecasts, and changes in an index of macroeconomic uncertainty. The VIX index is computed by the Chicago Board Options Exchange (CBOE) to reflect the implied volatility of a synthetic 1-month option written on the S\&P100 index and, as such, it constitutes a forwardlooking measure of expected uncertainty at the market level. The time-series of VIX was obtained from Bloomberg. Data on analysts' earnings forecasts were obtained from the Thomson I/B/E/S database. Finally, the time-series of Fama and French (1993) factors and the Carhart (1997) momentum factor were obtained from the website of Kenneth French, while the time-series of the index of macroeconomic uncertainty was obtained from the website of Turan Bali.

\section{Empirical Framework}

\subsection{Portfolio formation}

If cross-sectional dispersion is a priced risk factor, then we would expect that stocks with different sensitivities to changes in cross-sectional dispersion will offer different returns on average. We measure the sensitivity of each stock to $\triangle C S D$ by estimating the following timeseries regression

$$
r_{i . t}^{e}=a+\beta_{i, M K T} M K T_{t}+\beta_{i, \Delta C S A D} \Delta C S A D_{t}+\varepsilon_{i, t}
$$

where $r_{i . t}^{e}$ is the excess return of stock $i$ at time $t, M K T_{t}$ is the excess return of the market at $t$, and $\beta_{i, M K T}$ and $\beta_{i, \triangle C S A D}$ are the loadings of stock $i$ on market risk and cross-sectional dispersion risk, respectively. We estimate (6) separately for each stock and we include only one additional factor, namely the excess market return, in the pre-formation regressions since our objective is to extract the stocks' sensitivities to our main factor of interest $\triangle C S D$, rather than determining the set of all aggregate factors that could potentially have explanatory power for the cross- 
section of stock returns. Moreover, as argued by Ang et al. (2006), including more than two factors in the pre-formation regressions might add a significant amount of noise when constructing our portfolios. It should be noted that, although only one additional factor is included at this stage of the methodology, our post-formation regressions control for a much wider set of cross-sectional factors in order to evaluate how $\triangle C S D$ is priced in stock returns.

At the beginning of every month, we sort all stocks into quintiles according to their crosssectional dispersion betas, with the $\beta_{i, \triangle C S A D}$ of each stock $i$ having been estimated through the regression in (6) using daily returns for that stock over the past month. The pre-formation regression is only run when a stock has at least 15 daily observations over the previous month. Using daily data over a 1-month window in order to compute factor loadings is a commonly adopted compromise between accounting for the time-varying nature of loadings and estimating coefficients with some degree of precision (Pastor and Stambaugh, 2003; Ang et al., 2006). The first quintile includes stocks that have the lowest (most negative) dispersion betas while the fifth quintile consists of stocks that have the highest betas. Inside each quintile we value-weigh the monthly returns of individual stocks in order to compute the average quintile post-formation return over that month. This approach allows us to construct five time-series that refer to the monthly returns of stock portfolios that are significantly different in terms of their sensitivity to cross-sectional dispersion risk. We also construct two portfolios based on the sign of the stocks' dispersion betas, denoted by $\mathrm{N}$ and $\mathrm{P}$ for negative and positive betas, respectively. The returns of the $\mathrm{N}$ and $\mathrm{P}$ portfolios are also value-weighted averages of individual stock returns.

\subsection{Portfolio returns}

Table I reports the monthly total returns of the five quintile portfolios (Panel A) and those of two spread portfolios (Panel B). The first spread portfolio is labelled "1-5" and it involves a long position in the lowest-beta stocks in the first quintile and a short position in the highest-beta stocks in the last quintile. The second spread portfolio is labelled "N-P" and it involves a long position in stocks with negative dispersion betas and a short position in stocks with positive betas. The first two columns of Panel A report the mean and standard deviation of each quintile portfolio's returns. The third column reports the average pre-formation beta. The fourth column reports the average post-formation beta of the portfolio, which is obtained by estimating equation (6) using daily returns during the same month as when the portfolio's monthly return 
is computed. The fifth column reports the average market value of each portfolio as a percentage of the total market value across all five portfolios. Panel B reports the mean monthly returns and the associated t-statistics (in brackets) of the two spread portfolios.

The results are suggestive of a negative price for aggregate dispersion risk. Stocks in the first quintile, which have the lowest pre-formation betas ( -6.85 on average), offer a mean monthly return of $1.37 \%$ with a standard deviation of $7.39 \%$. At the other end, the highest-beta stocks in the fifth quintile (average beta is 6.71) offer the lowest mean return of $0.43 \%$ per month. More importantly, mean returns decrease monotonically with the level of past dispersion betas as we move from the first to the fifth quintile portfolio.

Furthermore, the simple strategy of going long in the lowest-betas stocks and short in the highest-beta ones is found to offer a mean return of $0.94 \%$ per month, which is statistically significant at the $1 \%$ level, with a standard deviation of $4.77 \%$. Investing in the N-P portfolio offers a lower mean return (0.49\% per month) which is, nevertheless, statistically significant. In order to put the returns of these two spread portfolios into perspective, it should be noted that they represent zero-cost positions and that the aggregate market return during the same period was $0.52 \%$ per month (with a standard deviation of $4.62 \%$ ).

For the moment, these results are not conclusive that dispersion risk is priced in the crosssection of stock returns, since the reported negative monotonic relationship refers to mean returns and past loadings. Some preliminary evidence that returns co-vary negatively with concurrently estimated betas is provided by the finding that post-formation dispersion betas increase as we move from the first to the fifth quintile. The post-formation betas are much less dispersed than the pre-formation ones, ranging from a minimum of -0.03 for the first quintile to a maximum of 0.22 for the fifth one. This finding is similar to the relationship between preand post-formation loadings of aggregate volatility risk reported by Ang et al. (2006). Overall, the fact that portfolio returns are decreasing monotonically with the level of their concurrent sensitivity to changes in cross-sectional dispersion is consistent with the existence of a negative dispersion premium. We explore this relationship in greater depth in the next Section.

\section{Controlling for Risks and Idiosyncratic Characteristics}

\subsection{Risk-adjusted returns}

In order to establish that aggregate dispersion risk is priced in the cross-section, we need to show that the relationship between dispersion loadings and mean returns is robust to other 
aggregate factors that have been commonly found to explain the cross-section of stock returns. More specifically, it is possible that the significant returns offered by the 1-5 spread portfolio (and, to a lesser extent, by the N-P portfolio) could simply represent compensation for exposure to some other known source of risk. We explore this hypothesis by regressing the time-series of portfolio returns on a set of commonly used systematic factors, as given by equation (7)

$$
r_{p, t}=\alpha_{p}+\beta_{p, s y s t}^{\prime} F_{t}+\varepsilon_{p, t}
$$

where $r_{p, t}$ is the monthly return of the portfolio and $F_{t}$ is a vector of aggregate risk factors, consisting of the excess market return $M K T$, the two additional Fama and French (1993) factors $S M B$ and $H M L$, and the Carhart (1997) momentum factor MOM. The vector of coefficients $\beta_{p, s y s t}^{\prime}$ is intended to capture the extent to which the returns of the portfolio can be explained by exposure to the set of systematic factors. The results are presented in Table II, with the first (second) column reporting the estimated coefficients and their associated $t$-statistics in brackets for the 1-5 (N-P) portfolio. All the systematic factors represent traded portfolios and the intercept from the time-series regression in (7) can be interpreted as mispricing relative to the factor model. In other words, the estimated alphas are the risk-adjusted returns of the portfolio, after accounting for its exposure to a set of aggregate risk factors.

The results from estimating (7) confirm that the returns of the 1-5 spread portfolio are not simply compensation for exposure to other systematic factors. The coefficients of all factors are statistically insignificant at the 5\% level, for both the 1-5 and the N-P portfolios. More importantly, the risk-adjusted return of going long in the lowest-beta portfolios and going short in the highest-beta ones is $0.55 \%$. This alpha is lower than the total return of $0.94 \%$ which was previously reported for the 1-5 portfolio, but it is statistically significant ( $\mathrm{t}$-stat $=2.87$ ), supporting the hypothesis of dispersion risk being priced in the cross-section. The results are weaker for the N-P portfolio, which is found to earn a statistically insignificant risk-adjusted return of $0.10 \%$ per month $(\mathrm{t}$-stat $=1.64)$ after accounting for its covariance with the systematic factors.

\subsection{Stock characteristics}

After establishing that the 1-5 spread portfolio offers returns in excess of its exposure to systematic risk factors, we examine the impact of stock characteristics. Although aggregate 
dispersion risk seems to command a premium in excess of those associated with other systematic risk factors, it could still be the case that our results are driven by the characteristics (other than their dispersion betas) of the specific stocks that populate our quintile portfolios. Our first test is based on estimating cross-sectional regressions similar to those in Brennan et al. (1998) and Goyal and Saretto (2009). We begin by running first-pass time-series regressions of the excess returns of individual stocks against the systematic factors (MKT, SMB, HML and $M O M$ ), as given in equation (8). We run one regression per stock $i$ using the full sample of excess monthly returns $r_{i, t}^{e}$.

$$
r_{i, t}^{e}=\alpha_{i}+\beta_{i}^{\prime} F_{t}+\varepsilon_{i, t}
$$

After obtaining the full-sample loadings of each stock to each of the four systematic factors from the first-pass regressions, we perform cross-sectional regressions of risk-adjusted returns against a set of idiosyncratic stock characteristics as given in equation (9)

$$
r_{i, t}^{e}-\widehat{\beta}_{l}^{\prime} F_{t}=\gamma_{0, t}+\gamma_{1, t}^{\prime} Z_{i, t-1}+u_{i, t}
$$

where $\beta_{i}^{\prime}$ is the vector of estimated factor loadings from the first-pass time-series regressions, $F_{t}$ is the vector of factor values and $Z_{i, t}$ is the vector of idiosyncratic characteristics of stock $i$ at time $t$. The stock characteristics in $Z_{i, t}$ comprise our main variable of interest $\beta_{\triangle C S A D}$, as well as the size (log market capitalization in millions), an idiosyncratic momentum factor (given by the past 6-month stock return), the standard deviation, skewness and kurtosis of stock returns over the past six months, the dispersion of analysts' forecasts about the stock's future earnings normalized by the mean forecast (similar to Diether et al., 2002), a liquidity measure, the percentage of stock returns explained by systematic risk, as well as the coskewness and idiosyncratic volatility of stock returns. ${ }^{3}$ The vector of stock characteristics is

\footnotetext{
${ }^{3}$ We follow Pastor and Stambaugh (2003) and measure the liquidity of a given stock $i$ as the coefficient $\gamma_{i, t}$ from the following regression

$$
r_{i, t+1}^{e}=\theta_{i, t}+\varphi_{i, t} r_{i, t}+\gamma_{i, t} \operatorname{sign}\left(r_{i, t}^{e}\right) v_{i, t}+\varepsilon_{i, t+1}
$$

where $v_{i, t}$ is the dollar volume of stock $i$ at $t$. The proportion of stock returns explained by systematic risk is measured by the $\bar{R}^{2}$ of the first-pass time-series regressions of excess stock returns against the four systematic factors, as described in equation (8). We follow Harvey and Siddique (2000) and measure the co-skewness of individual stock returns in a given month as
} 
lagged by one period and we estimate one cross-sectional regression per month. Table III reports the mean estimated coefficients from these monthly cross-sectional regressions, their t-statistics (in brackets) and the mean Adjusted R squared.

Consistent with our previous results, the stocks' sensitivity to changes in dispersion is significant in explaining their subsequent risk-adjusted returns. The mean coefficient of the dispersion beta is negative and statistically significant ( $\mathrm{t}$-stat $=-2.28$ ), indicating that stocks that have higher sensitivities to changes in dispersion tend to earn lower returns than their less sensitive counterparts, after accounting for systematic risk factors and idiosyncratic characteristics. Furthermore, size and co-skewness are found to be the only other characteristics (apart from $\beta_{\triangle C S A D}$ ) that seem to be significantly related to risk-adjusted stock returns at the $5 \%$ level ( $\mathrm{t}$-stat $=-2.54$ ), with stocks of larger companies or stocks that exhibit lower (more negative) co-skewness with the market offering on average lower risk-adjusted returns.

The second test involves the construction of double-sorted portfolios. For each of the previously mentioned characteristics (plus the market beta), we sort stocks into quintiles according to the values of that particular characteristic at the beginning of a given month. Then, within each characteristic-based quintile, we further sort stocks into quintiles according to their dispersion betas (or into the two $\mathrm{N}$ and $\mathrm{P}$ portfolios). Finally, the monthly returns of the dispersion-based portfolios are averaged across each of the five characteristic-based quintiles. The two-way sorts are performed every month, resulting in a continuous time-series of monthly returns for five portfolios that have distinct sensitivities to dispersion risk. This double-sorting is replicated separately for each of the idiosyncratic stock characteristics mentioned above.

The advantage of double-sorting is that, in contrast to the portfolios discussed in Section 3, each double-sorted portfolio with a particular mean dispersion beta has been populated by stocks that, by construction, vary in terms of some other characteristic. This addresses the potential concern that the previously reported pattern of portfolio returns declining monotonically across dispersion betas might be driven by stocks with certain features overpopulating different portfolios. However, the main limitation of double-sorting is that we

$$
\text { coskew }=\frac{E\left[\varepsilon_{i, t}\left(r_{m k t, t}^{e}\right)^{2}\right]}{\sqrt{E\left[\left(\varepsilon_{i, t}\right)^{2}\right]} E\left[\left(r_{m k t, t}^{e}\right)^{2}\right]}
$$

where $\varepsilon_{i, t}$ is the residual from the time-series regression of excess stock returns $r_{i, t}^{e}$ against excess market returns $r_{m k t, t}^{e}$. We follow Ang et al. (2006) and measure the monthly idiosyncratic volatility of individual stock returns in a given month as the standard deviation of the residuals obtained from the first-pass time-series regressions described in equation (8). This set of regressions is estimated per stock per month, using daily observations. 
can only control for one characteristic at a time.

Table IV reports the mean monthly return of double-sorted 1-5 and N-P portfolios. Each row corresponds to the specific characteristic that was used for the first sort. The mean returns of the two spread portfolios vary across different characteristics, for instance with mean returns for the 1-5 portfolio ranging from $0.59 \%$ (first sorted on co-skewness) to $1.10 \%$ (first sorted on size). Similarly, the mean returns of the N-P portfolio range from $0.26 \%$ (first sorted on idiosyncratic momentum) to $0.73 \%$ (first sorted on the dispersion of analysts' forecasts). By comparison, the unconditional sorts only on dispersion betas that were presented in Section 3 were found to offer mean monthly returns of $0.94 \%$ and $0.49 \%$ for the $1-5$ and N-P portfolios, respectively. Overall, even though mean portfolio returns appear to covary with certain stock characteristics, this relationship is not enough to subsume the explanatory power of dispersion betas on expected returns. This is especially the case for the 1-5 spread portfolio, which is found to offer statistically significant and quite large mean returns (always in excess of $0.64 \%$ ) across all double sorts. Finally, in unreported results (available from the authors upon request) we find that the negative monotonic relationship between dispersion betas and mean quintile returns is robust across all stock characteristics used for the double sorts.

\subsection{Robustness}

In this Section we further investigate the robustness of our results. Table $\mathrm{V}$ reports the mean returns and alphas (risk-adjusted returns, estimated as in Section 4.1) of the 1-5 and N-P spread portfolios under a set of alternative settings. The first robustness check refers to the portfolio's formation period. More specifically, the previously reported negative monotonic relationship between mean returns and dispersion betas has been based on using daily data over the previous month to estimate pre-formation factor loadings $\beta_{\triangle C S A D}$. As can be seen from the Table, the results become somewhat weaker when the formation period increases. For example, if dispersion betas are estimated using the previous three months of daily returns, then the resulting 1-5 portfolio offers a mean monthly return of $0.44 \%$ with an alpha of $0.31 \%$, compared to $0.94 \%$ and $0.55 \%$, respectively, when the formation period was one month. The results are even weaker for longer formation windows, with a similar pattern observed for the N-P portfolio.

This finding of a weaker relationship between dispersion betas and expected returns as the formation period increases is most likely the result of obtaining less precise estimates of stocks' 
sensitivities to changes in dispersion as more data is used. Extending the formation period means that past returns observations that are more distant are being added in the estimation, leading to conditional estimates of stocks' betas that are less relevant at the time when the portfolios are constructed. Selecting the optimal formation period is an empirical issue and it ultimately depends on the time-variation of conditional betas. However, a formation period of one month using daily data represents a typically adopted choice, attempting to optimize the trade-off between obtaining more precise beta estimates and decreasing turnover in the resulting portfolios (see also Ang et al., 2006).

We also replicate the analysis of 1-5 and N-P portfolio returns by dividing the full sample into two sub-samples based on the sign of the excess market return. We find that both spread portfolios offer higher mean returns during months of positive market returns compared to negative ones. For instance, the 1-5 portfolio offers a mean return of $1.20 \%$ during up-market months compared to $0.50 \%$ during down-market months, while a similar difference is observed in terms of risk-adjusted returns (alphas are $0.87 \%$ and $0.34 \%$ during positive and negative market returns, respectively). This result is somewhat surprising, especially since (in unreported results) we find that there is no discernible pattern across the quintile portfolios in terms of their average pre-formation market betas. It should be noted however, that mean portfolio returns and risk-adjusted returns are highly significant in both sub-samples. Overall, these results suggest that a significant relationship between dispersion risk and expected returns exists irrespective of the direction of the market, although the exact strength of this relationship seems to vary with the sign of the market return.

We observe a similar pattern for the 1-5 portfolio when we split the sample according to the sign of the main variable $\triangle C S A D$. Going long in the lowest-beta stocks and short in the highestbeta ones is found to offer higher returns on average during months of positive changes in dispersion (1.22\% versus $0.77 \%$ ), with alphas also being higher during months with positive dispersion changes compared to negative ones ( $0.75 \%$ vs $0.38 \%)$. This stronger performance of the 1-5 portfolio during months with positive dispersion changes is not completely independent from the previous finding of the portfolio returns being higher during months of positive market returns, since the two conditioning variables $M K T$ and $\triangle C S D$ are positively correlated. However, the opposite pattern is observed for the N-P portfolio, the returns of which are actually higher during months with negative changes in dispersion, although the difference between mean returns was not found to be statistically significant.

As was mentioned in Section 3, we use the first difference of the cross-sectional dispersion 
series as our aggregate risk factor because the level variable CSD is highly serially correlated. We investigate the robustness of this choice by computing changes in dispersion as the innovations from a simple AR(1) model fitted on CSD. The AR model is fitted at every point in time $t$ using all available data on dispersion up to $t$-1, so no contemporaneous or forwardlooking information is used when we form AR-based expectations of dispersion at $t$. When the innovations from the AR model are used as an aggregate risk factor, the results are very similar to those previously reported. The 1-5 portfolio earns a mean total and risk-adjusted return of $0.91 \%$ and $0.77 \%$ per month, respectively, which are comparable to those reported in Table I. The results for the N-P portfolio are also similar to, and even slightly stronger than, those previously reported using first differences of CSD.

Our main findings are also robust to industry groupings. Unreported results suggest the absence of any obvious over-concentration of any particular industry group across our quintile portfolios. We also re-estimate the returns of the two spread portfolios by eliminating one industry group in turn from the sample. The results are virtually identical to those reported in the full sample, suggesting that the significant returns stemming from a dispersion premium are not driven by any specific industry group.

\section{The Price of Aggregate Dispersion Risk}

\subsection{Constructing a dispersion mimicking factor}

Table I shows that stocks with lower past loadings on aggregate dispersion risk tend to offer higher returns than stocks with higher loadings. Moreover, this relationship cannot be explained by a set of systematic factors (Table II) or by the stocks' idiosyncratic characteristics (Tables III and IV). The monotonic relationship between expected returns and past sensitivities to changes in dispersion points towards a significant negative premium for bearing aggregate dispersion risk. Given these findings, we proceed to measure the cross-sectional price of dispersion risk.

In order to compute the price of aggregate dispersion risk in the cross-section, we want to create an investible portfolio that can capture the time variation of changes in dispersion. We follow Breeden et al., (1989), Lamont (2001) and Ang et al. (2006) to compute a dispersion mimicking factor. More specifically, we create the mimicking factor FCSD by running a timeseries regression of our variable of interest $\triangle C S D$ against the returns of a set of base assets, namely the five quintile portfolios discussed in the previous sections, as follows 


$$
\triangle C S A D_{t}=c+b^{\prime} P_{t}+\varepsilon_{t}
$$

where $P_{t}$ refers to the returns of the five dispersion-based portfolios. The vector of slope coefficients $b^{\prime}$ reflects the sensitivity of each base asset to changes in dispersion. We estimate the regression in (10) every month using daily data, and we then use the estimated $b$ coefficients to compute the value of the mimicking factor for that month as $\widehat{b^{\prime}} P_{t}$. In other words, the factor FCSD that mimics changes in cross-sectional dispersion is given by the returns of a portfolio that consists of positions in the five quintile portfolios in proportion to their sensitivity to dispersion changes.

We also construct an alternative mimicking factor by following the standard factor-forming technique introduced by Fama and French (1993). On each month, we sort all stocks into two groups based on their market capitalization. We then sort stocks, independently of the first sort, into three groups according to their dispersion betas. The intersection of these two sorts produces six portfolios that differ in terms of size and sensitivity to dispersion. The mimicking factor is, then, given as the value-weighted average return of the two high-beta portfolios minus the value-weighted average return of the two low-beta portfolios (see also Bali et al., 2015). The results from this alternative dispersion factor are similar to using FCSD and are, thus, not reported for brevity.

\subsection{Estimating the market price of dispersion risk}

We employ the standard Fama-MacBeth (1973) two-pass methodology to extract the risk premium of aggregate dispersion risk from the cross-section of stock returns. First, we construct a set of assets that are reasonably different in terms of their sensitivity to changes in dispersion. The test assets are double-sorted on market beta and dispersion beta as follows. At the beginning of each month, we run univariate regressions of excess stock returns against the excess returns of the market using daily data over the previous month. We use the estimated market betas $\beta_{M K T}$ to sort the stocks into quintiles. We also run bivariate regressions of excess stock returns against excess market returns and the dispersion factor, constructed as the mimicking portfolio discussed above, again using daily data over the previous month. Then, within each $\beta_{M K T}$-based quintile, we further sort stocks into quintiles according to their dispersion betas $\beta_{F C S A D}$. Overall, we obtain the time-series of monthly returns of 25 double- 
sorted investible portfolios.

In the first stage, we regress the excess returns of each of the 25 test portfolios against a set of systematic factors in the full sample, as in equation (7). The second stage involves estimating a cross-sectional regression of mean portfolio excess returns against the betas that were obtained from the first-pass time-series regressions. The vector $\lambda^{\prime}$ of estimated coefficients from the second-pass cross-sectional regression (11) represents the unconditional prices of risk for the set of aggregate risk factors. Table VI reports the estimated coefficients, t-statistics (in brackets) and Adjusted R squared of the second-pass regression. Overall, we test for a number of different factor sets in order to better understand the robustness of our results.

$$
\overline{r_{p}^{e}}=\lambda_{o}+\lambda^{\prime} \beta_{p, s y s t}^{\prime}+u_{p}
$$

The first column of the Table (Regression I) presents the results from estimating a model that consists of the 3 Fama-French (1993) factors (MKT, SMB, HML), the Carhart (1997) momentum factor (MOM) and our dispersion factor (FCSD). The $M K T$ and $S M B$ factors are found to earn a positive and statistically significant premium, as is the MOM factor. However, the estimated risk premium of the $H M L$ factor is, albeit positive, statistically indistinguishable from zero, possibly due to the mixed performance of the value effect during our sample period. More importantly, the estimated $\lambda$ of $F C S D$ confirms the prediction of a negative premium for bearing dispersion risk. The price of dispersion risk is found to be $-0.10 \%$ per month, which is statistically significant at the 5\% level, supporting the hypothesis that exposure to aggregate dispersion risk commands a premium in the cross-section of stock returns.

Regression II is augmented by the Pastor and Stambaugh (2003) aggregate liquidity factor FLIQ. Consistent with existing evidence from the literature, aggregate liquidity is found to be priced in the cross-section, as reflected by a significantly positive risk premium. Furthermore, the premium associated with aggregate dispersion risk remains negative $(-0.10 \%)$ and statistically significant.

\subsection{Controlling for alternative measures}

We find cross-sectional dispersion to be associated with a significantly negative risk premium. However, in order to conclude that dispersion is in fact a priced risk factor, we need to show that its explanatory power over the cross-section of stock returns cannot be accounted for by 
covariation with other systematic factors. Although FCSD was found to have explanatory power in excess of the standard MKT, SMB, HML, MOM and FLIQ factors, it could still be the case that dispersion proxies for some other source of aggregate risk. Given that the dispersion of stock returns, as computed in equation (1), is a measure of heterogeneity of beliefs about the future performance of stocks in the market, we look at measures of beliefs' heterogeneity or, alternatively, uncertainty as systematic factors that could potentially subsume the informational content of FCSD. Table VI reports the results of two-pass estimations of pricing models with these additional factors, while Table VII reports the pairwise correlations between factors. All factors have been computed as the returns of mimicking portfolios, similarly to the FCSD factor.

We begin by exploring the effect of market volatility. We use the implied volatility VIX index as a measure of aggregate volatility risk and we incorporate the mimicking portfolio FVIX (based on monthly changes $\triangle V I X$ ) as an additional factor in Regression III. Ang et al. (2006) also use the VIX as a proxy of aggregate volatility risk and they document a significantly negative premium for volatility risk in the cross-section of stock returns. In our sample, the two factors (FCSD and FVIX) exhibit a relatively strong positive correlation (0.43), which is also consistent with our finding of a negative dispersion risk premium and the finding by Ang et al. (2006) of a negative volatility risk premium. We confirm the presence of a negative premium for aggregate volatility risk $(-0.12 \%$ per month) which is, however, statistically insignificant. More importantly, the estimated premium for aggregate dispersion risk is still found to be negative, at a similar level to the one previously reported (-0.11\% per month) and statistically significant, even after controlling for volatility risk.

Next, we consider the effect of another measure of dispersion of beliefs by focusing on the mean dispersion of analysts' forecasts. We volume-weigh the stock-specific deviations of analysts' forecasts of future earnings (normalized by the mean forecast to address the effect of different scales) in order to construct an aggregate measure of dispersion of beliefs about the future earnings of stocks in the market (FDISP). We then use the first difference of this measure to create the mimicking portfolio FFDISP which is used as an additional factor in Regression IV. We would expect this new factor (FFDISP) to be highly positively correlated with our initial dispersion factor (FCSD), in the sense that both measures reflect changes in the level of the market's consensus (or lack of) regarding the future performance of the equity market. Somewhat surprisingly, the correlation coefficient between the two factors is only slightly larger than zero (0.03) and statistically insignificant. Consistent with our intuition, we find a negative, 
and marginally significant, risk premium for exposure to aggregate forecast dispersion risk. Moreover, the risk premium of our original factor of cross-sectional dispersion in stock returns is still found to be negative $(-0.11 \%)$ and statistically significant $(\mathrm{t}$-stat $=-2.48)$.

We also consider the stock variance SVAR, which is computed as the sum of squared returns for each stock, averaged across all stocks. Guo (2006) documents a significant risk premium associated with SVAR, while Welch and Goyal (2009) find that this premium is insignificant in a longer sample period. We use its first difference $\triangle S V A R$ to construct the mimicking portfolio FSVAR that is used as an additional factor in Regression V. As expected, FSVAR is strongly positively correlated with FCSD (correlation coefficient is 0.34 ) and it is associated with a negative premium $(-0.03 \%$ per month). However, the FSVAR premium is statistically insignificant at any meaningful level. Furthermore, FCSD is still found to have explanatory power over the cross-section of stock returns, with the dispersion risk premium being at a similar level as in the previous estimations $(-0.11 \%$ per month) and statistically significant $(\mathrm{t}-$ stat is -2.55).

We also augment the specification by introducing the Bali et al. (2015) index of macroeconomic uncertainty. This uncertainty index $U N C$ is constructed by using the dispersion of analysts' forecasts with respect to a set of seven key macroeconomic variables (see Bali et al., 2015, for more details). The forecasts are drawn from the Survey of Professional Forecasters, and the $U N C$ index represents an ex-ante measure of dispersion of expectations regarding the general macroeconomic environment. We include the mimicking factor FUNC as an additional regressor in Regression VI. The factor based on the dispersion in the cross-section of stock returns FCSD is found to be slightly negatively correlated with the factor on the dispersion in macroeconomic forecasts FUNC (correlation coefficient is -0.12). We find that macroeconomic uncertainty is associated with a significantly negative risk premium in the cross-section (0.61\% per month), consistent with the findings reported by Bali et al. (2015). Moreover, the dispersion risk premium remains statistically significant and at the same level, after accounting for the effect of macroeconomic uncertainty.

The final factor that we consider represents a potentially more direct alternative proxy for aggregate idiosyncratic risk, measured as the mean idiosyncratic stock volatility. More specifically, we follow the common approach of measuring idiosyncratic volatility of stock returns as the standard deviation of the residuals from regressing returns against systematic factors (see, for instance, Fu, 2009). At the end of each month, we regress the daily excess returns of a given stock against the 3 Fama and French (1993) factors, the Carhart (1997) 
momentum factor, our dispersion factor FCSAD and the Pastor and Stambaugh (2003) liquidity factor FLIQ. We run one time-series regression per stock per month, as long as a given stock has at least 15 observations in that month. The standard deviation of the regression's daily residuals for each stock-month (multiplied with the square root of the number of daily observations in that month in order to express it in monthly terms) represents the idiosyncratic volatility of that stock during that month. We then use the cross-sectional mean of individual stocks' idiosyncratic volatilities for a given month as a measure of idiosyncratic volatility at the aggregate level during that month.

After converting the time-series of cross-sectional means to a mimicking portfolio (FIDVOL), we include this aggregate idiosyncratic volatility factor in the augmented Regression VII. As can be seen from the Table, the idiosyncratic volatility factor FIDVOL is associated with a negative risk premium in the cross-section of stock returns (-0.18\% per month), which is to be expected for a variable that proxies for aggregate idiosyncratic risk. Nevertheless, with a t-statistic of 1.49 , this risk-premium is statistically insignificant. Somewhat surprisingly, we also find that the idiosyncratic volatility factor FIDVOL is only weakly correlated with our dispersion factor FCSD (correlation is 0.03). More importantly, though, the risk-premium of the dispersion factor is still found to be statistically significant and at a similar level (approximately $-0.10 \%$ ) even after including the aggregate idiosyncratic volatility as an additional regressor. Overall, our empirical results suggest that the cross-sectional dispersion of stock returns is associated with a significant risk-premium in the cross-section of expected stock returns, and one that is distinct from premia associated with a relatively large set of commonly used systematic factors.

\section{Conclusion}

This study proposes a new state variable that appears to be priced in the cross-section of stock returns. This new variable is measured as the cross-sectional dispersion of stock returns around the market return, and it has been attracting increasing attention in the literature in relation to idiosyncratic risk. Given that dispersion reflects aggregate idiosyncratic risk at the market level, we hypothesize that it should be priced in the cross-section and we discuss why it is expected to be associated with a negative risk premium. Our empirical results strongly support this hypothesis.

More specifically, stocks are found to offer expected returns that vary according to their sensitivity to changes in dispersion. Stocks with higher "dispersion" betas offer lower mean 
returns compared to stocks with lower betas. Furthermore, a zero-cost spread portfolio that is long in low-beta stocks and short in high-beta ones is found to offer a return of $11.3 \%$ per annum. Based on a Fama-French-Carhart alpha of 6.3\% per annum, a significant portion of this portfolio's performance cannot be explained by common systematic factors. We estimate the price of risk for this state variable to be $-0.11 \%$ per month $(-1.3 \%$ per annum) in the crosssection of stock returns, which is statistically significant and economically large when compared to the prices of other risk factors that have been examined in previous studies.

Finally, we show that these results are robust to a wide set of systematic factors, idiosyncratic characteristics, and methodological variations. The results from two-pass regressions of individual stock returns and from double-sorted portfolios demonstrate that the reported negative relationship between returns and sensitivity to dispersion holds after accounting for several stock-specific characteristics. More importantly, we show that the reported dispersion premium is distinct from premia that have been previously found to be offered by other systematic factors which are related to uncertainty or heterogeneity, such as volatility, dispersion of analysts' earnings forecasts, mean stock variance, macroeconomic uncertainty and the mean idiosyncratic volatility of stock returns.

Overall, our results suggest that the cross-sectional dispersion of stock returns is negatively associated with the investment and consumption opportunity set. A likely explanation for this could be that, since dispersion is driven by stocks' idiosyncratic shocks, it acts as a proxy for aggregate idiosyncratic risk. This source of risk is expected to affect investors who do not hold diversified portfolios (as has been previously argued by Goyal and Santa-Clara, 2003), and they would bid up the prices of stocks that can serve as hedges by offering returns that vary positively with dispersion, resulting in a negative dispersion premium. Another related explanation could be that dispersion is negatively associated with the effectiveness of crosshedges. When the returns of individual stocks are more dispersed around the market return, cross-hedging using index futures becomes less effective. Consequently, investors who would like to hedge their non-diversified portfolios would be willing to pay a premium to hold assets that pay their highest returns when dispersion increases and their ability to cross-hedge decreases. 


\section{References}

Ang, A., Hodrick, R., Xing, Y. and X. Zhang, 2006. The cross-section of volatility and expected returns. Journal of Finance 61, 259-299

Angelidis, T., Sakkas, A. and N. Tessaromatis, 2015. Stock market dispersion, the business cycle and expected factor returns. Journal of Banking and Finance, forthcoming

Bali, T., Brown, S. and Y. Tang, 2015. Macroeconomic uncertainty and expected stock returns. Working Paper

Bali, T., Cakici, N., Yan, X. and Z. Zhang, 2005. Does idiosyncratic risk really matter?. Journal of Finance 60, 905-929

Bernales, A. and M. Valenzuela, 2016. Implied correlation and market returns. Working Paper

Bernales, A., Verousis, T. and N. Voukelatos, 2016. Do investors follow the herd in option markets? Journal of Banking and Finance, forthcoming

Bessembinder, H., 1992. Systematic risk, hedging pressure, and risk premiums in futures markets. Review of Financial Studies 5, 637-677

Bhootra, A., 2011. Are momentum profits driven by the cross-sectional dispersion I expected stock returns?. Journal of Financial Markets 14, 494-513

Breeden, D., Gibbons, M. and R. Litzenberger, 1989. Empirical tests of the consumption-oriented CAPM. Journal of Finance 44, 231-262

Brennan, M., Chordia, T. and A. Subrahmanyam, 1998. Alternative factor specifications, security characteristics, and the cross-section of expected returns. Journal of Financial Economics 49, 345373

Buss, A., Schoenleber, L. and G. Vilkov, 2017. Option-implied correlations, factor models, and market risk. Working Paper

Cai, F., Han, S. and D. Li, 2012. Institutional herding in the corporate bond market. Board of Governors of the Federal Reserve System, International Finance Discussion Paper no 1701

Cao, J. and B. Han, 2016. Idiosyncratic risk, costly arbitrage, and the cross-section of stock returns. Journal of Banking and Finance 73, 1-15

Carhart, M., 1997. On persistence in mutual fund performance. Journal of Finance 52, 57-82

Chen, J. Kannan, P., Loungani, P. and B. Trehan, 2011. New evidence on cyclical and structural sources of unemployment. IMF working paper

Chen, Z. and R. Petkova, 2012. Does idiosyncratic risk proxy for risk exposure?. Review of Financial Studies 25, 2745-2787

Chiang, T. and D. Zheng, 2010. An empirical analysis of herd behaviour in global stock markets. Journal of Banking and Finance 34, 1911-1921

Chichernea, D., Ferguson, M. and H. Kassa, 2015. Idiosyncratic risk, investor base, and returns. Financial Management 44, 267-293

Connolly, R. and C. Stivers, 2003. Momentum and reversals in equity-index returns during periods of abnormal turnover and return dispersion. Journal of Finance 58, 1521-1555

Diether, K. Malloy, C. and A. Scherbina, 2002. Differences of opinion and the cross-section of stock returns. Journal of Finance 57, 2113-2141

Fama, E. and K. French, 1993. Common risk factors in the returns of stocks and bonds. Journal of Financial Economics 33, 3-56

Fama, E. and J. Macbeth, 1973. Risk return, and equilibrium: Empirical tests. Journal of Political Economy 71, 607-636

Galariotis, E., Rong. W. and S. Spyrou, 2015. Herding on fundamental information: A comparative study. Journal of Banking and Finance 50, 589-598 
Garcia, R., Mantilla-Garcia, D. and L. Martellini, 2014. A model-free measure of aggregate idiosyncratic volatility and the prediction of market returns. Journal of Financial and Quantitative Analysis 49, 1133-1165

Goyal, A. and P. Santa-Clara, 2003. Idiosyncratic risk matters!. Journal of Finance 58, 975-1008

Goyal, A. and A. Saretto, 2009. Cross-section of option returns and volatility. Journal of Financial Economics 94, 310-326

Guo, H., 2006. On the out-of-sample predictability of stock market returns. Journal of Business 79, 645670

Guo, H. and R. Savickas, 2008. Average idiosyncratic volatility in G7 countries. Review of Financial Studies $21,1259-1296$

Harvey, C. and A Siddique, 2000. Conditional skewness in asset pricing tests. Journal of Finance 55, 12631295

Lamont, O., 2001. Economic tracking portfolios. Journal of Econometrics 105, 161-184

Levy, H., 1978. Equilibrium in an imperfect market: A constraint on the number of securities in the portfolio. American Economic Review 68, 643-658

Maio, P., 2015. Cross-sectional return dispersion and the equity premium. Hanken School of Economics working paper

Malkiel, B. and Y. Xu, 1997. Risk and return revisited. Journal of Portfolio Management 23, 9-14

Malkiel, B. and Y. Xu, 2005. Idiosyncratic risk and security returns. Working Paper, University of Texas at Dallas

Merton, R., 1987. A simple model of capital market equilibrium with incomplete information. Journal of Finance 42, 483-510

Pastor, L. and R. Stambaugh, 2003. Liquidity risk and expected stock returns. Journal of Political Economy $111,642-685$

Pollet, J. and M. Wilson, 2010. Average correlation and stock market returns. Journal of Financial Economics 96, 364-380

Stivers, C. and L. Sun, 2010. Cross-sectional return dispersion and time variation in value and momentum premiums. Journal of Financial and Quantitative Analysis 45, 987-1014

Wei, I. and C. Zhang, 2005. Idiosyncratic risk does not matter: A re-examination of the relationship between average returns and average volatilities. Journal of Banking and Finance 29, 603-621

Welch, I. and A. Goyal, 2008. A comprehensive look at the empirical performance of equity premium prediction. Review of Financial Studies 21, 1455-1508 


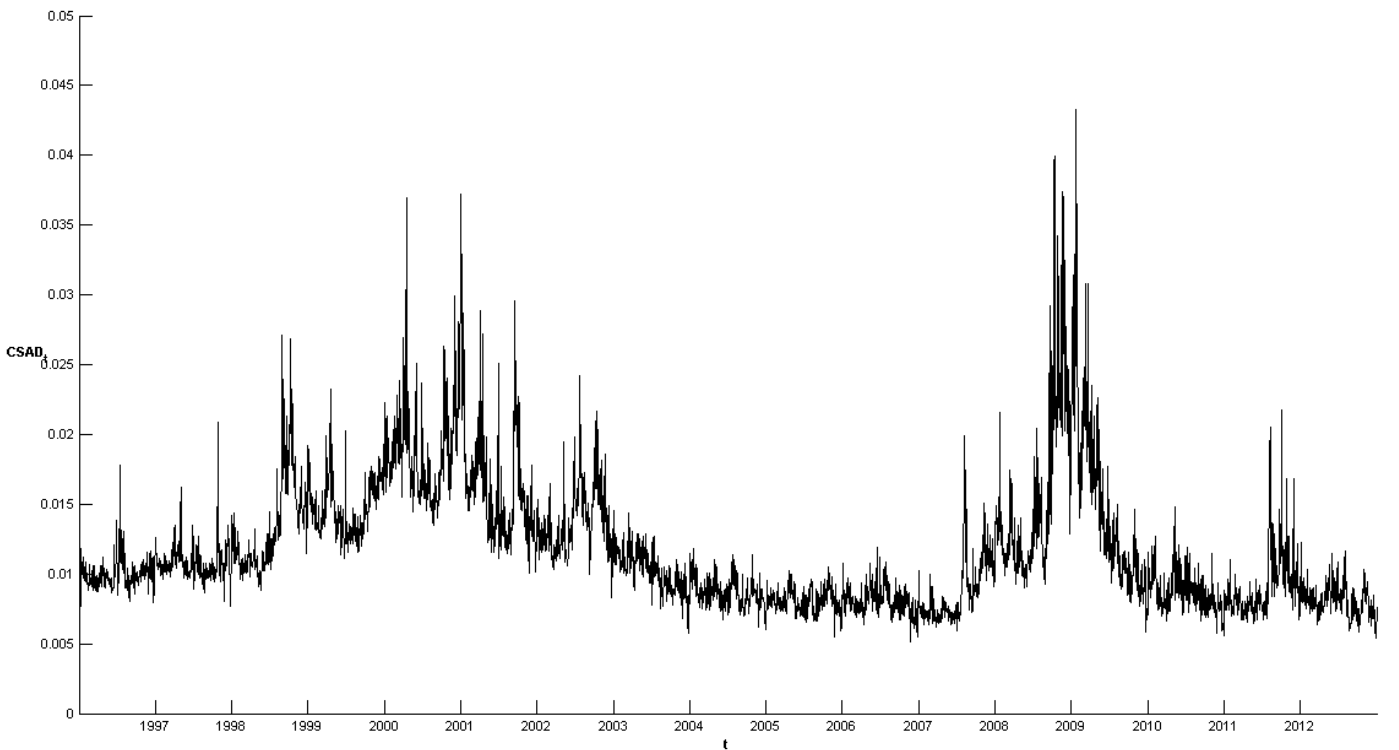

Figure 1: Time-series of CSD

This Figure plots the daily time-series of cross-sectional dispersion of stock returns. The sample period is January 1996 to December 2012. 


\section{Table I}

Returns of sorted and spread portfolios

\begin{tabular}{|c|c|c|c|c|c|}
\hline & Mean & Std.dev. & $\begin{array}{l}\text { Pre-formation } \\
\beta_{\triangle C S A D}\end{array}$ & $\begin{array}{l}\text { Post-formation } \\
\beta_{\triangle C S A D}\end{array}$ & $\begin{array}{c}\text { Mkt Share } \\
(\%)\end{array}$ \\
\hline \multicolumn{6}{|c|}{ Panel A: Sorted Portfolios } \\
\hline 1 & 0.0137 & 0.0739 & -6.85 & -0.03 & 0.14 \\
\hline 2 & 0.0118 & 0.0752 & -2.19 & 0.06 & 0.22 \\
\hline 3 & 0.0076 & 0.0464 & 0.06 & 0.10 & 0.25 \\
\hline 4 & 0.0065 & 0.0496 & 2.30 & 0.19 & 0.24 \\
\hline 5 & 0.0043 & 0.0649 & 6.71 & 0.22 & 0.15 \\
\hline \multicolumn{6}{|c|}{ Panel B: Spread Portfolios } \\
\hline $1-5$ & $\begin{array}{c}0.0094 \\
(2.82)\end{array}$ & & & & \\
\hline $\mathrm{N}-\mathrm{P}$ & $\begin{array}{c}0.0049 \\
(2.28)\end{array}$ & & & & \\
\hline
\end{tabular}

This Table reports the monthly returns of portfolios that have been formed according to their exposure to $\triangle C S D$ risk. For every month, we run the following time-series regression for every stock using daily returns over the previous month

$$
r_{i, t}-r_{f, t}=\alpha+\beta_{i, M K T} M K T_{t}+\beta_{i, \Delta C S A D} \Delta C S A D_{t}+\varepsilon_{i, t}
$$

We sort stocks into quintiles according to their $\beta_{\triangle C S A D}$, from lowest (quintile 1 ) to highest (quintile 5 ), and we compute value-weighted monthly total (not excess) returns of each quintile portfolio in Panel A. Pre-formation betas refer to the value-weighted $\beta_{\triangle C S A D}$ within each quintile portfolio at the beginning of the month. Post-formation betas are estimated from running the same time-series regression using daily portfolio returns during the same month. We also sort stocks into two groups labelled $\mathrm{P}$ and $\mathrm{N}$, corresponding to positive and negative dispersion betas, respectively. Panel $\mathrm{B}$ reports the mean return and t-statistic of two spread portfolios. The first spread portfolio goes long in the first quintile portfolio and short in the last quintile portfolio from Panel A. The second spread portfolio goes long in stocks with negative betas and short in stocks with positive ones. 
Table II

Risk-adjusted returns of spread portfolios

\begin{tabular}{ccc} 
& $1-5$ & $\mathrm{~N}-\mathrm{P}$ \\
\cline { 2 - 3 } constant & 0.0055 & 0.0010 \\
MKT & $(2.87)$ & $(1.64)$ \\
& 0.1003 & 0.1039 \\
SMB & $(1.21)$ & $(1.37)$ \\
& -0.2441 & -0.2021 \\
$H M L$ & $(-1.75)$ & $(-1.70)$ \\
& -0.0819 & -0.0649 \\
MOM & $(-0.46)$ & $(-0.65)$ \\
& 0.133 & 0.0978 \\
$\bar{R}^{2}$ & $(1.30)$ & $(1.18)$ \\
& 0.05 & 0.07
\end{tabular}

This Table reports the results from regressing the monthly returns of two spread portfolios (constructed as described in Table I) against a set of systematic factors.

$$
r_{p, t}=\alpha_{p}+\beta_{p, s y s t}^{\prime} F_{t}+\varepsilon_{p, t}
$$

$F_{t}$ is the vector of systematic factors comprising the Fama and French (1993) three factors ( $M K T, S M B$ and $H M L)$ and the Carhart (1997) momentum factor (MOM). We report the estimated coefficients and their t-statistics (in brackets) using Newey and West (1987) standard errors. The last row reports the Adjusted R squared. 
Table III

\section{Risk-adjusted stock returns controlling for stock characteristics: two-pass regressions}

\begin{tabular}{cc}
\hline constant & 0.0077 \\
$\beta_{\triangle C S A D}$ & $(2.14)$ \\
size & -0.0001 \\
& $(-2.28)$ \\
$r_{\text {mom }}$ & 0.0000 \\
& $(-2.54)$ \\
std.dev & 0.0009 \\
& $(0.47)$ \\
skewness & 0.0420 \\
& $(0.36)$ \\
kurtosis & -0.0001 \\
& $(-0.96)$ \\
forecast dispersion & 0.0000 \\
& $(-0.22)$ \\
liquidity & 0.0001 \\
& $(1.18)$ \\
systematic risk $\%$ & -5.6118 \\
& $(-0.87)$ \\
co-skewness & 0.0189 \\
& $(1.90)$ \\
idiosyncratic volatility & -0.0022 \\
$\bar{R}^{2}$ & $(-2.47)$ \\
\end{tabular}

This Table reports the results from cross-sectional regressions of monthly risk-adjusted stock returns on a set of stock characteristics

$$
r_{i, t}^{e}-\widehat{\beta_{l}^{\prime}} F_{t}=\gamma_{0, t}+\gamma_{1, t}^{\prime} Z_{i, t-1}+u_{i, t}
$$

The betas are obtained from time-series regressions of stock returns on a set of systematic factors

$$
r_{i, t}^{e}=\alpha_{i}+\beta_{i}^{\prime} F_{t}+\varepsilon_{i, t}
$$

The systematic factors are the Fama and French (1993) three factors (MKT, SMB and $H M L$ ) and the Carhart (1997) momentum factor $(M O M)$. The vector $\beta_{i}^{\prime}$ refers to the factor loadings obtained from a single full-sample time-series regression per stock. The stock characteristics are the beta of cross-sectional dispersion $\left(\beta_{\triangle C S A D}\right.$, computed as described in Table I), size (market capitalization in \$ billion), a stock-specific momentum factor ( $r_{\text {mom }}$, given as the stock return over the previous 6 months), the standard deviation, skewness and kurtosis of stock returns over the previous 6 months, the dispersion of analysts' forecasts (normalized), the Pastor and Stambaugh (2003) liquidity measure, the percentage of stock returns explained by systematic risk (given as the $\bar{R}^{2}$ of the first-stage time-series regressions), the co-skewness of stock returns with market returns, and the idiosyncratic volatility of stock returns. We run one cross-sectional regression per month. The table reports the mean estimated coefficients and their t-statistics (in brackets) based on Newey and West (1987) standard errors, as well as the mean Adjusted R squared. 
Table IV

Stock returns controlling for stock characteristics: double-sorted portfolios

\begin{tabular}{ccc}
\hline & $1-5$ & $\mathrm{~N}-\mathrm{P}$ \\
\cline { 2 - 3 }$\beta_{M K T}$ & 0.0086 & 0.0053 \\
size & 0.0110 & 0.0060 \\
$r_{\text {mom }}$ & 0.0076 & 0.0026 \\
std.dev & 0.0078 & 0.0056 \\
skewness & 0.0064 & 0.0033 \\
kurtosis & 0.0101 & 0.0051 \\
forecast dispersion & 0.0109 & 0.0073 \\
liquidity & 0.0103 & 0.0029 \\
systematic risk \% & 0.0070 & 0.0037 \\
co-skewness & 0.0059 & 0.0029 \\
idiosyncratic volatility & 0.0084 & 0.0034 \\
\hline
\end{tabular}

This Table reports the mean returns of double-sorted portfolios. On each month, we first sort all stocks into quintiles according to a particular characteristic (as presented in Table III). Then, stocks in each characteristic-based quintile are further sorted into quintiles according to their dispersion betas and into two portfolios according to the betas' sign (as described in Table I). The dispersion-based portfolios are averaged across each of the five characteristic-based portfolios, resulting in a set of continuous time-series of monthly returns. The first column reports the time-series mean returns of a portfolio going long in the lowest beta stocks and short in the highest beta ones. The second column reports the time-series mean of a portfolio going long in stocks with negative betas and short in stocks with positive ones. Each row corresponds to a specific characteristic used for the first sort. 
Table V

Robustness

\begin{tabular}{|c|c|c|c|c|c|}
\hline & & \multicolumn{2}{|c|}{$1-5$} & \multicolumn{2}{|c|}{$\mathrm{N}-\mathrm{P}$} \\
\hline & & mean & alpha & mean & alpha \\
\hline \multicolumn{6}{|c|}{ formation window } \\
\hline & 3 months & 0.0044 & 0.0031 & 0.0044 & 0.0005 \\
\hline & 6 months & 0.0025 & 0.0011 & 0.0042 & 0.0001 \\
\hline & 12 months & 0.0027 & 0.0019 & 0.0028 & 0.0003 \\
\hline \multicolumn{6}{|l|}{$M K T$ sign } \\
\hline & negative & 0.0050 & 0.0034 & 0.0021 & 0.0005 \\
\hline & positive & 0.0120 & 0.0087 & 0.0065 & 0.0045 \\
\hline \multicolumn{6}{|l|}{$\triangle C S D$ sign } \\
\hline & negative & 0.0077 & 0.0038 & 0.0056 & 0.0017 \\
\hline & positive & 0.0122 & 0.0075 & 0.0039 & 0.0008 \\
\hline \multicolumn{6}{|l|}{ changes in $C S D$} \\
\hline
\end{tabular}

This Table reports the mean monthly returns and risk-adjusted returns (alphas) of two spread portfolios under a set of robustness checks. The spread portfolios are constructed as described in Table I, and alphas are computed as described in Table II. The first panel reports portfolio returns under three alternative windows for computing pre-formation betas $\left(\beta_{\triangle C S A D}\right)$ when sorting stocks into portfolios. The second panel reports portfolio returns conditional on the sign of excess market returns. The third panel reports portfolio returns conditional on the sign of changes in crosssectional dispersion. The fourth panel reports portfolio returns when changes in dispersion have been computed as the innovations from an AR(1) model. 
Table VI

The price of cross-sectional dispersion risk

\begin{tabular}{|c|c|c|c|c|c|c|}
\hline & I & II & III & IV & $\mathrm{V}$ & VI \\
\hline constant & $\begin{array}{c}-0.011 \\
(-0.55)\end{array}$ & $\begin{array}{l}-0.018 \\
(-1.36)\end{array}$ & $\begin{array}{l}-0.018 \\
(-1.39)\end{array}$ & $\begin{array}{l}-0.010 \\
(-0.66)\end{array}$ & $\begin{array}{l}-0.011 \\
(-0.71)\end{array}$ & $\begin{array}{l}-0.017 \\
(-0.66)\end{array}$ \\
\hline MKT & $\begin{array}{c}0.141 \\
(-4.35)\end{array}$ & $\begin{array}{c}0.154 \\
(-5.30)\end{array}$ & $\begin{array}{c}0.153 \\
(-5.88)\end{array}$ & $\begin{array}{c}0.125 \\
(-3.69)\end{array}$ & $\begin{array}{c}0.127 \\
(-3.79)\end{array}$ & $\begin{array}{c}0.140 \\
(-2.44)\end{array}$ \\
\hline$S M B$ & $\begin{array}{c}0.135 \\
(-2.24)\end{array}$ & $\begin{array}{c}0.129 \\
(-3.86)\end{array}$ & $\begin{array}{c}0.129 \\
(-3.03)\end{array}$ & $\begin{array}{c}0.086 \\
(-1.56)\end{array}$ & $\begin{array}{c}0.083 \\
(-1.25)\end{array}$ & $\begin{array}{r}0.086 \\
-(1.27)\end{array}$ \\
\hline$H M L$ & $\begin{array}{c}0.032 \\
(-0.68)\end{array}$ & $\begin{array}{l}-0.009 \\
(-0.26)\end{array}$ & $\begin{array}{l}-0.010 \\
(-0.30)\end{array}$ & $\begin{array}{l}-0.049 \\
(-1.31)\end{array}$ & $\begin{array}{l}-0.051 \\
(-1.22)\end{array}$ & $\begin{array}{l}-0.040 \\
(-0.70)\end{array}$ \\
\hline MOM & $\begin{array}{c}0.286 \\
(-2.92)\end{array}$ & $\begin{array}{c}0.254 \\
(-4.53)\end{array}$ & $\begin{array}{c}0.256 \\
(-3.83)\end{array}$ & $\begin{array}{c}0.234 \\
(-3.19)\end{array}$ & $\begin{array}{c}0.227 \\
(-2.30)\end{array}$ & $\begin{array}{c}0.213 \\
(-2.04)\end{array}$ \\
\hline$F C S D$ & $\begin{array}{l}-0.097 \\
(-2.44)\end{array}$ & $\begin{array}{l}-0.095 \\
(-2.45)\end{array}$ & $\begin{array}{l}-0.091 \\
(-2.68)\end{array}$ & $\begin{array}{l}-0.105 \\
(-2.81)\end{array}$ & $\begin{array}{l}-0.106 \\
(-3.17)\end{array}$ & $\begin{array}{l}-0.097 \\
(-3.22)\end{array}$ \\
\hline FLIQ & & $\begin{array}{c}0.151 \\
(-2.24)\end{array}$ & $\begin{array}{c}0.135 \\
(-1.14)\end{array}$ & $\begin{array}{c}0.123 \\
(-0.83)\end{array}$ & $\begin{array}{c}0.134 \\
(-1.01)\end{array}$ & $\begin{array}{c}0.105 \\
(-1.14)\end{array}$ \\
\hline FVIX & & & $\begin{array}{l}-0.117 \\
(-1.47)\end{array}$ & $\begin{array}{l}-0.101 \\
(-1.26)\end{array}$ & $\begin{array}{l}-0.099 \\
(-1.12)\end{array}$ & $\begin{array}{l}-0.098 \\
(-1.47)\end{array}$ \\
\hline FFDISP & & & & $\begin{array}{l}-0.018 \\
(-1.97)\end{array}$ & $\begin{array}{l}-0.018 \\
(-1.49)\end{array}$ & $\begin{array}{l}-0.017 \\
(-0.63)\end{array}$ \\
\hline FSVAR & & & & & $\begin{array}{l}-0.022 \\
(-0.39)\end{array}$ & $\begin{array}{l}-0.006 \\
(-0.35)\end{array}$ \\
\hline FUNC & & & & & & $\begin{array}{l}-0.563 \\
(-1.12)\end{array}$ \\
\hline $\bar{R}^{2}$ & 0.89 & 0.90 & 0.90 & 0.90 & 0.90 & 0.90 \\
\hline
\end{tabular}

This Table reports the Fama-MacBeth (1973) factor premia on 25 equity portfolios, which have been sorted first on their $\beta_{m k t}$ and then on their $\beta_{\triangle C S A D}$. The factors comprise the excess market return MKT, the two additional Fama-French (1993) factors SMB and HML, the Carhart (1997) momentum factor MOM, the Pastor and Stambaugh (2003) aggregate liquidity measure FLIQ, innovations in the cross-sectional returns dispersion FCSD, monthly innovations in the implied volatility index FVIX, innovations in aggregate forecast dispersion FFDISP, innovations in the mean variance of individual stocks FSVAR, and innovations in the Bali et al. (2015) macroeconomic uncertainty index FUNC. The table presents the loadings obtained from the second-pass crosssectional regression, with t-statistics based on Newey-West (1987) standard errors reported in brackets. Each loading is reported as the coefficient times 100, so that it can be interpreted as the monthly percentage return. The last row reports the Adjusted R squared. 


\section{Table VII}

Factor Correlations

\begin{tabular}{cccccccccccc}
\hline & $F C S D$ & $F V I X$ & FFDISP & FSVAR & FUNC & FIDVOL & MKT & SMB & HML & MOM & FLIQ \\
\cline { 2 - 11 } FCSD & 1.00 & 0.43 & 0.03 & 0.34 & -0.12 & 0.03 & -0.40 & -0.08 & 0.09 & 0.40 & 0.02 \\
FVIX & 0.43 & 1.00 & 0.02 & 0.31 & -0.17 & -0.04 & -0.57 & -0.21 & 0.15 & 0.28 & 0.02 \\
FFDISP & 0.03 & 0.02 & 1.00 & 0.02 & -0.05 & -0.06 & 0.01 & 0.03 & 0.06 & -0.02 & -0.05 \\
FSVAR & 0.34 & 0.31 & 0.02 & 1.00 & -0.12 & 0.01 & -0.15 & -0.02 & 0.03 & 0.14 & 0.04 \\
FUNC & -0.12 & -0.17 & -0.05 & -0.12 & 1.00 & 0.23 & 0.17 & 0.09 & 0.01 & -0.24 & -0.06 \\
FIDVOL & 0.03 & -0.04 & -0.06 & 0.01 & 0.23 & 1.00 & -0.07 & 0.03 & -0.09 & -0.08 & 0.62 \\
\hline
\end{tabular}

This Table reports the correlations between monthly values of a set of pricing factors. The factors comprise the excess market return $M K T$, the two additional Fama-French (1993) factors $S M B$ and $H M L$, the Carhart (1997) momentum factor MOM, the Pastor and Stambaugh (2003) aggregate liquidity measure FLIQ, innovations in the cross-sectional returns dispersion FCSD, monthly innovations in the implied volatility index FVIX, innovations in aggregate forecast dispersion FFDISP, innovations in the mean variance of individual stocks FSVAR, and innovations in the Bali et al. (2015) macroeconomic uncertainty index FUNC, and changes in the aggregate idiosyncratic stock volatility FIDVOL. 